\title{
Research on Online Destination Image of Zhenjiang Section of the Grand Canal Based on Network Content Analysis
}

\author{
Yan Yang ${ }^{1}$, Chunfa Sha ${ }^{1, *}$, Wencheng Su ${ }^{2}$ and Edwin Kofi Nyefrer Donkor ${ }^{1}$ (I) \\ 1 School of Art, University of Jiangsu, Zhenjiang 212013, China; 2221920012@stmail.ujs.edu.cn (Y.Y.); \\ getteown@yahoo.com (E.K.N.D.) \\ 2 Institute of Science and Technology Information, University of Jiangsu, Zhenjiang 212013, China; \\ bao5ye@ujs.edu.cn \\ * Correspondence: shachunfa@ujs.edu.cn
}

Citation: Yang, Y.; Sha, C.; Su, W.; Donkor, E.K.N. Research on Online Destination Image of Zhenjiang Section of the Grand Canal Based on Network Content Analysis. Sustainability 2022, 14, 2731 https://doi.org/10.3390/ su14052731

Academic Editors: Flávio Gomes Borges Tiago, Maria Teresa Borges Tiago, Beatriz Casais and Androniki Kavoura

Received: 31 January 2022

Accepted: 23 February 2022

Published: 25 February 2022

Publisher's Note: MDPI stays neutral with regard to jurisdictional claims in published maps and institutional affiliations.

Copyright: (C) 2022 by the authors. Licensee MDPI, Basel, Switzerland. This article is an open access article distributed under the terms and conditions of the Creative Commons Attribution (CC BY) license (https:// creativecommons.org/licenses/by/ $4.0 /)$.

\begin{abstract}
The Zhenjiang section of the Grand Canal (ZGC) is an important part of the Grand Canal, which was listed on the World Heritage List in 2014. The purpose of this study is to analyze the projected image of the ZGC constructed by destination marketing organizations (DMO) in the WeChat official account (WOA) by using the network content analysis method to condense the image features of the ZGC on the Internet and to provide support for the brand image construction of the ZGC from the supply side. The results show that: (1) DMO pay more attention to the shipping traffic and generate less publicity regarding the literature and art of the ZGC; (2) the cognitive images that are widely promoted are river course and water transport; the emotional images in high-frequency words are less involved but are positive as a whole; (3) the brand image of the ZGC has a strong nostalgic characteristic; (4) more attention should be paid to the heritage sites in the Song Dynasty and near the river course and river outlet.
\end{abstract}

Keywords: online destination image; network content analysis; Zhenjiang section of the Grand Canal; cultural heritage; DMO; WOA

\section{Introduction}

In recent years, cities along the Grand Canal have become some of the hot spots in tourism research. Zhenjiang is located at the intersection of the Yangtze River and the Grand Canal. The characteristics of the canal city in Zhenjiang are obvious, but its tourism development is relatively slow. The Jiangsu section of the Grand Canal where the ZGC is located has a large number, complete types and high density of cultural and tourism resources. However, the richer the types of resources, the more prone they are to homogenization [1]. A destination that lacks a unique brand image is unattractive and would not leave a deep impression on tourists [2]. The online destination image is an important determinant of tourism behavior, destination selection and online word-ofmouth in the social media era [3,4]. Whether marketing of the online destination image is successful or not, it affects tourists' evaluation of cultural heritage scenic spots and their willingness to visit [5]. In this case, the research on the online destination image of the ZGC has not attracted much attention from academia and industry. The characteristics of related cultural heritage scenic spots are unclear and not well known. Additionally, they lack core competitiveness compared with surrounding cities.

Since applying for the World Heritage Site, destination marketing organizations (DMO) have made great contributions to the dissemination of information and the shaping of the tourism image of the ZGC. The WeChat official account (WOA) is the main position for the research and construction of the ZGC. It is an important channel for potential tourists to understand and explore the culture of the ZGC. This paper used the big data mining method to mine the network data in the WOAs operated by DMO, analyzed the online destination image of the ZGC, refined its best competitive advantage resources, and formed a clear 
brand image. From the perspective of application: fully understanding the marketing situation of DMO can provide appropriate suggestions for the future development of the ZGC; measuring and evaluating the online destination image of the ZGC will help the government to shape the destination image efficiently and improve the travel intention of tourists; a deep analysis of key issues, such as destination management, marketing and heritage protection, can also enlighten other canal destinations. From the perspective of theory: an opportunity is provided to compare the consistency between the projected image and the perceived image; measuring the online destination image in the WOA platform promotes the two-dimensional structure of the destination image and expands the channel of construction of the destination image; using big data from social media to analyze the temporal and spatial distribution of cultural heritage innovatively will have specific guiding significance for heritage protection and tourism marketing.

\section{Literature Review}

\subsection{Online Destination Image and DMO}

Since the Internet has become the main channel of communication and information exchange in recent decades, more and more studies have introduced the concept of "online destination image". Mak defines "online destination image" as the "online representation of collective beliefs, knowledge, ideas, feelings and overall impression of a destination" [6]. Online content provides additional information, including blogs where travelers share their travel experiences and reports about destinations published by the news media $[7,8]$. This content provides an online resource library for exchanging some aspects of destinations and may influence affect tourists' choice of destination and revisit $[9,10]$.

UNWTO (World Tourism Organization) defines DMO as organizations responsible for the management and/or marketing of individual tourism destinations" [11]. DMO is the official representative of tourism destination promotion, including local tourism authorities and entrusted subordinate institutions and commercial companies, aiming at creating a strong and attractive brand image for its destination [12]. Previous studies have shown that DMO's marketing communication is an important factor in shaping the expected online destination image [13]. The content generated by DMO is a good source for understanding the expected online destination image [6].

DMO platforms influence tourists' destination choice by projecting positive destination images [14]. A large part of their content is targeted at potential tourists who have never been to the destination. Attracting audiences to understand the local culture and enhancing their visiting intention are the main goals of these institutions. At present, the relevant research on the online destination image of the Grand Canal is still dominated by user generated content (UGC) [15], which is effective for cities or scenic spots with mature tourism development. For the heritage sites that have not yet established a commercial tourism mode (such as the ZGC), DMO play a more obvious role in its brand image construction and promotion.

The online destination image can be understood from the perspective of destination (the projection image) and tourists (the perception image) [16]. The "projected image" in this paper refers to the image projected by DMO through marketing information (such as DMO website and WOAs sponsored by DMO), which is the combination of government authority and private business efforts. DMO's online platform is one of the most useful tools for studying the destination image [17]. In the past, researchers examined the production or projection of the destination image by paying attention to how marketers, tourism-related websites and DMOs use the Internet to promote destinations [18-20]. In this sense, the projected image can be conceptualized as the "brand image", which means reputation.

The online destination image is a more dynamic social construction than the projected image in traditional printed matter; hence, tourists are increasingly relying on online destination images projected by social media instead of brochures and guides [4]. Under the new media environment, local tourism administrations have launched a WeChat official account, Weibo, channel, etc. These online platforms become one of the commercial 
information sources for building online destination images. Social media such as WOA have the advantages of reliable information, timely information updates and a wide audience. This greatly ensures the vitality of online destination image construction, which has become the platform for DMO to provide major public services and an important marketing channel in China [16]. Promoting the expected online destination image through WOAs will help to improve the reputation and success of the destination.

\subsection{Cultural Heritage Tourism}

The Grand Canal, as a world-famous artificial river channel, is a typical cultural heritage [21]. Cultural heritage resources are invaluable for the development of a destination. With the increasing importance of connection between cultural heritage and tourism, cultural heritage scenic spots have become one of the most important tourism resources, which can attract tourists to specific tourism destinations [22]. Although many canals have changed from shipping waterways to tourist destinations, little is known about the contemporary phenomenon of canal tourism in academic circles. There is still a lack of research on the destination image when the canal was transformed into a tourist destination [23].

One of the key points in cultural heritage tourism research is how to enhance the attraction of cultural heritage sites [24-26]. Tourists are the main body to explain cultural heritage resources. Therefore, their attraction to tourists does not come directly from their true features but from how people look at them, that is, tourists' perception [27]. Different motivations and social demographic characteristics of tourists will make them have different perceptions and experiences [28-30]. Moreover, some external attributes or marketing modes of heritage sites also affect the attractiveness of cultural heritage. At present, many studies have confirmed the influence of uniqueness, familiarity, and communication mode of heritage on attraction.

(1) Uniqueness: Ekinci and Hosany assert that the personality characteristics of the destination are directly related to the attraction of the destination because they can identify and measure the personality of the destination [31]. The uniqueness of heritage will also have a positive impact on tourists' experience, enhance the visiting intention of potential tourists and enhance regional competitiveness [32]. Ginting claims that landmark, which is part of the uniqueness of heritage tourism, plays a key role in enhancing the city identity to make it more attractive and recognizable [33].

(2) Familiarity: Shubert's research shows that the more familiar the cultural heritage elements of a single destination are, the more positive its evaluation of tourism attraction is [27]. This relationship has been confirmed in many years of scientific research [34-37]. In addition, familiarity will also increase the details of the visual memory of the place [38]. Therefore, establishing an attractive image of a previously unknown scenic spot is a great challenge because potential tourists tend to underestimate it [39].

(3) Communication mode: The communication mode of heritage is very important for potential tourists who are interested in more specific matters in specific areas [40]. An attractive and functional heritage display is very important for successful media coverage. In this respect, information design is of great importance in explaining, displaying and spreading heritage. It urges tourists to pay more attention to the exclusivity and unique heritage of a place [40].

To sum up, the attraction of cultural heritage sites can be improved at least through information design and landmark setting. Therefore, when developing cultural heritage, local management strategies are essential, including creating clear destination image positioning and selecting appropriate information dissemination methods.

\section{Materials and Methods}

\subsection{Research Object}

Zhenjiang section of the Grand Canal (ZGC) has been opened to navigation for more than 2200 years. Zhenjiang is one of the earliest areas where the canal was dug in China, 
and it is also the river outlet of the Jiangnan Canal, as shown in Figure 1. Nowadays, ZGC is the river section with the largest traffic volume in the Jiangnan Canal, and it is also one of the important hubs connecting the north and south of the canal. On the bank of Ancient Canal in Zhenjiang, there are more than 90 cultural heritage sites, including the confluence of rivers, Granary in Song and Yuan Dynasties, Zhaoguan Stone Tower and the former site of the British Consulate. Numerous heritage assets are the main source of canal tourism.

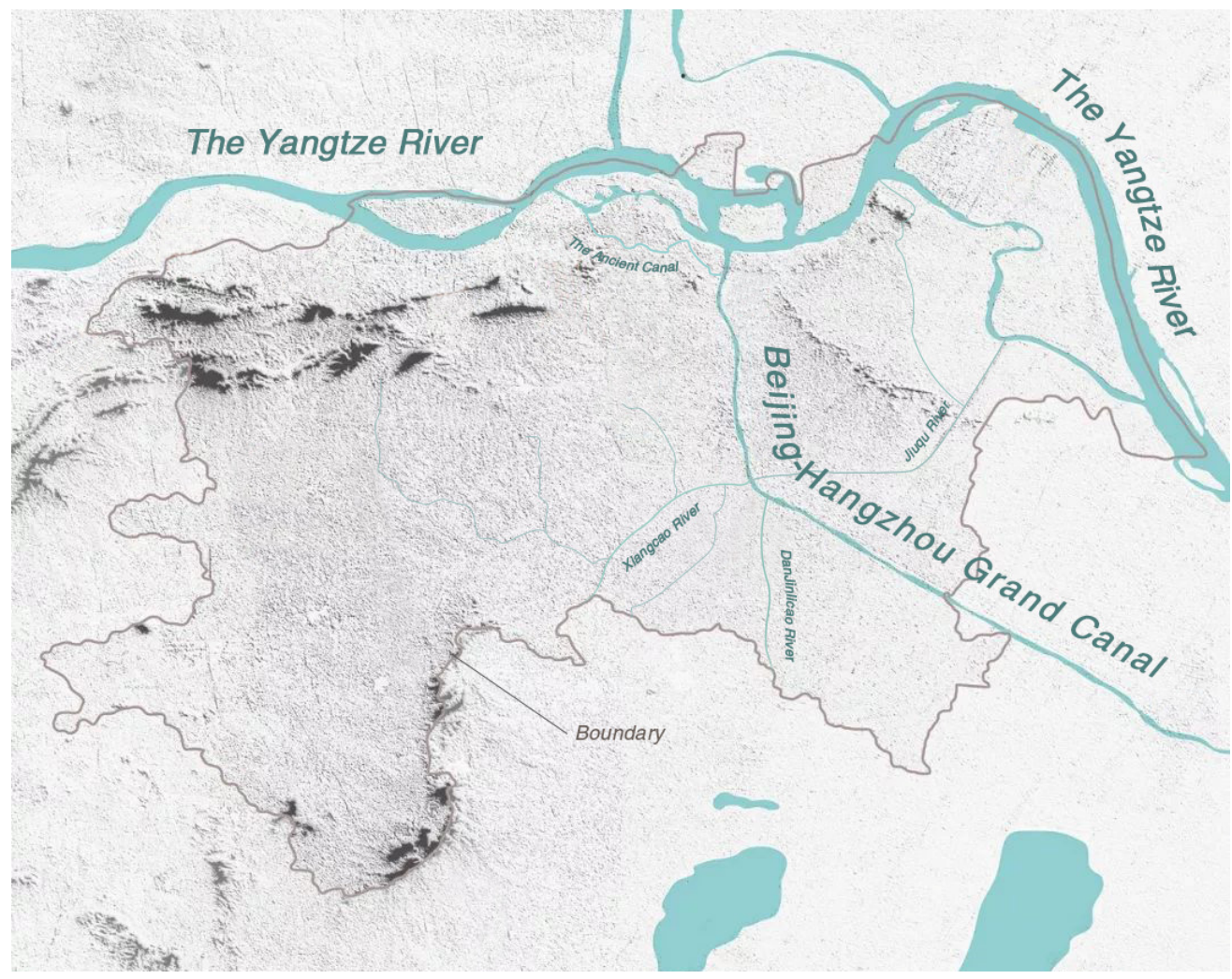

Figure 1. Location of Zhenjiang section of the Grand Canal.

The "Fourteenth Five-Year Plan for the Protection, Inheritance and Utilization of Culture of the Grand Canal" recently issued by the Chinese National Development and Reform Commission proposed to achieve a deep integration of culture and tourism of the Grand Canal by 2025. Although ZGC has profound cultural value and strong attraction to global tourists, researchers have not yet explored ZGC too much. The research status of its online destination image is still lagging behind the policy requirements. Therefore, this research used the content of WOAs operated by DOM as the information source and extracted the image characteristics of the online destination of ZGC based on network content analysis. The research content was specifically classified into the following areas: (1) mining the characteristics and themes of high-frequency image; (2) analyzing the cognitive and emotional part of online destination image; (3) analyzing the temporal and spatial distribution of different types of cultural heritage resources.

\subsection{Data Collection}

Text mining technology comes from the fields of data mining and natural language processing (NLP). In recent years, the research technology is mainly based on machine learning and deep learning, which play a decisive role in the improvement of NLP. Design of text mining in this article consisted of the following steps:

(1) Collection and screening of samples. All the data in this article were obtained using a web-text mining tool developed by Python. Samples were all from articles published by WOAs. Researchers adopted the top 200 articles containing the keywords 
"Zhenjiang section of the Grand Canal" in WOA because the similarity increased and the correlation decreased extremely after these 200 articles. The collected data contained article title, article content, publishing time and name of WOA. This paper strictly limited the source of articles and number of words, excluding articles from educational institutions, photographers' associations, personal media platforms and short articles with less than 200 words. In addition, every article content had been manually screened many times, and the articles that did not meet the research purpose, such as photography exhibition, activity report, social news, conference, speech and online voting, were excluded. After manual screening of repetitive, irrelevant and too-short content, a total of 119,618 words were obtained. WOAs mainly included those operated by local government agencies, such as Zhenjiang Style, Danyang Daily, Zhenjiang Release and others operated by commercial institutions related to canal, such as Canal Network (as shown in Table 1).

(2) Data cleaning. The researchers and several relevant experts of ZGC used the triangular mutual evidence method to compile the user-defined dictionary jointly. This study used jieba word segmentation software to segment Chinese sentences and remove specific characters, such as stop words, spaces, line breaks and punctuation. Several coders filtered out meaningless words and merged synonyms at the same time. The corresponding operation would not be carried out unless they reached an agreement on inclusion/exclusion. This method effectively reduces the wrong word segmentation. It is necessary to check and improve the segmentation results many times until a satisfactory result is obtained, specifically including filtering out meaningless words, merging synonyms and supplementing the custom dictionary to ensure the correctness and comprehensiveness of the proper nouns and improve the reliability of similarity calculation.

Table 1. Top 5 WOAs source of text mining.

\begin{tabular}{|c|c|c|c|}
\hline WOAs & $\begin{array}{l}\text { Number of } \\
\text { Articles }\end{array}$ & $\begin{array}{c}\text { Reading Times in } \\
\text { Total }^{2}\end{array}$ & $\begin{array}{l}\text { Recommended } \\
\text { Times in Total }\end{array}$ \\
\hline Canal Network & 8 & 1690 & 35 \\
\hline Zhenjiang Style & 5 & 18,555 & 435 \\
\hline Danyang Daily & 4 & 30,871 & 261 \\
\hline Zhenjiang Release & 2 & 4024 & 31 \\
\hline Jingjiang Evening News & 2 & 843 & 7 \\
\hline
\end{tabular}

${ }^{1}$ The data statistics time is up to 24 August 2020. ${ }^{2}$ The data statistics time is up to 10 November 2021.

\subsection{Text Analysis}

Compared with traditional questionnaire surveys, text analysis has the advantage of obtaining rich data and more objective analysis results. It analyzes and studies the text through non-intrusive methods, which can use the obtained data for different aspects of research and analysis to provide a research foundation for the deconstruction of destination image and the inheritance of heritage value. The process of text analysis is divided into the following parts and is represented in Figure 2:

Firstly, through word frequency and theme analysis, this study obtains the hot spots and classification of projection images. Specifically, the composition of the top 50 highfrequency words is analyzed, and the distribution of keywords with different parts of speech is compared. In addition, the projected image is manually divided into different categories, and the sum of word frequency of the top 20 high-frequency words in each theme is taken. Through this investigation, we can understand DMO's marketing strategy and help it adjust its marketing direction in time.

Secondly, the relationship between cognitive and emotional image was shown through social network analysis. The composition of tourist destination image proposed by Balogulu and McCleary includes three basic dimensions: cognitive image, emotional image and the overall image composed of them [41]. As far as online content is concerned, the cognitive 
part may be expressed through nouns or information about the object, while the emotional part may be expressed through adjectives or information related to subjective feelings [42]. Social network refers to a collection of points and connections between points, revealing the actual or potential relationship between high-frequency words. In the study of He et al., they constructed an associative semantic network based on the co-occurrence of nouns and adjectives from UGC. This method effectively reflects the internal relationship between cognitive and emotional image [14]. This article used Ucient6.0 to generate a centrality measure for each adjective and noun [43] and summarized the overall image of ZGC based on centrality.

Finally, this article also completed a cross-analysis on the spatio-temporal distribution and word frequency of cultural heritage, and some enlightening results could be obtained. Through literature search and interviews with experts to classify and sort out the cultural heritage in the network content, the researchers selected 70 most typical cultural heritages and used the Echarts open-source visualization library to make the sunburst chart. Król stated that the potential level of cultural heritage can be determined by the value of selected variables, such as the number of heritage items, the kinds of food of specific cultural significance and the extensive cultural infrastructure [44]. Therefore, the enriched bubble chart produced by the ggplot 2 is used to illustrate the changes in the number and activity of different types of heritage over time, while the heat map made by ArcGIS is used to obtain the law of word frequency in geographical location.
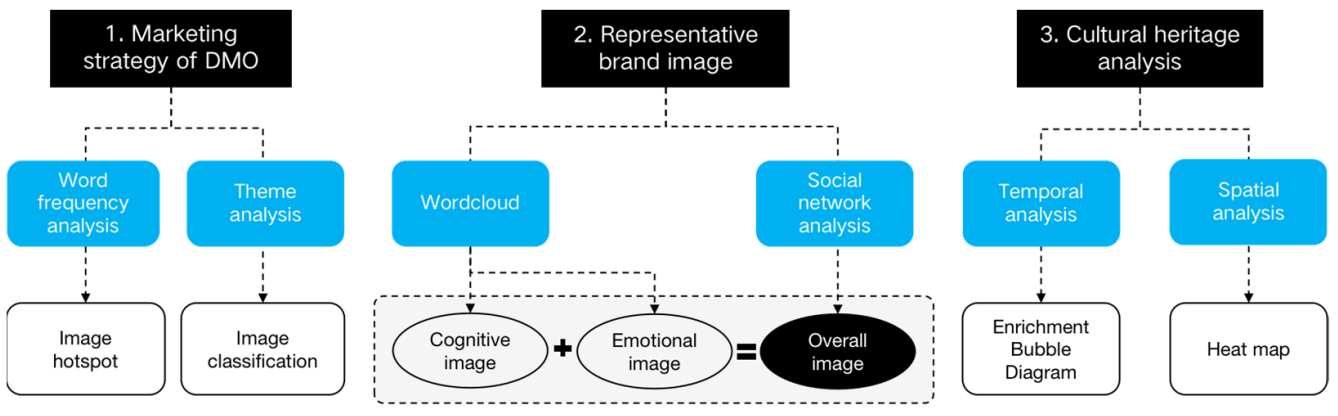

Figure 2. Process of data analysis.

\section{Results}

\subsection{High Frequency Word Analysis}

Through the word frequency analysis of the network text, 50 high-frequency words of the ZGC were obtained (as shown in Table 2). The high-frequency words reflected hot spots of the projected image of the ZGC. The results show that the terms with the highest frequency of the projected images in the ZGC were "Zhenjiang", "The Grand Canal", "Danyang", "Culture" and "History". The frequency reached more than 200 times. Overall, high-frequency words were composed of nouns, adjectives and verbs. Among them, there were 45 nouns, accounting for $90 \%$, the highest proportion of the total, mainly related to cultural heritage, scenic spots and hydraulic facilities. The verbs in the text mainly referred to the manager's planning behavior, accounting for $8 \%$, around the four aspects, namely "Develop", "Protect", "Excavate" and "Inherit". The adjectives mainly involved DMO's evaluation and the position of the ZGC, accounting for only $2 \%$. 
Table 2. Word frequency of high frequency words.

\begin{tabular}{|c|c|c|c|c|c|}
\hline No. & Feature Words & Frequency & No. & Feature Words & Frequency \\
\hline 1 & Zhenjiang & 841 & 26 & Sunan Canal & 59 \\
\hline 2 & The Grand Canal & 809 & 27 & Ship & 56 \\
\hline 3 & Danyang $^{1}$ & 299 & 28 & Jingkou Sluice & 56 \\
\hline 4 & Culture & 243 & 29 & $\begin{array}{l}\text { Zhenjiang section } \\
\text { Confluence of Grand }\end{array}$ & 54 \\
\hline 5 & History & 221 & 30 & $\begin{array}{c}\text { Canal and Qiantang } \\
\text { River }\end{array}$ & 53 \\
\hline 6 & The Yangtze River & 166 & 31 & Lian Lake & 53 \\
\hline 7 & The ancient canal & 157 & 32 & Ecology & 48 \\
\hline 8 & Develop & 128 & 33 & Water conservancy & 46 \\
\hline 9 & Xijin Ferry & 123 & 34 & Yangzhou & 46 \\
\hline 10 & Jiangnan Canal & 116 & 35 & Channel & 45 \\
\hline 11 & $\begin{array}{l}\text { Beijing-Hangzhou } \\
\text { Grand Canal }\end{array}$ & 105 & 36 & Jiangsu & 44 \\
\hline 12 & Jiangnan & 97 & 37 & Stone Carving & 42 \\
\hline 13 & Jianbi & 88 & 38 & Water transport & 41 \\
\hline 14 & Protect & 85 & 39 & Yunyang & 41 \\
\hline 15 & Jingkou & 83 & 40 & Shipping & 40 \\
\hline 16 & $\begin{array}{c}\text { Grand Canal cultural } \\
\text { belt }\end{array}$ & 81 & 41 & Tuyang Canal & 40 \\
\hline 17 & Ruins & 79 & 42 & Bridge & 39 \\
\hline 18 & $\begin{array}{l}\text { Zhenjiang section of } \\
\text { the Grand Canal }\end{array}$ & 78 & 43 & Jiaoshan & 39 \\
\hline 19 & River course & 68 & 44 & Jinshan & 38 \\
\hline 20 & North and south & 64 & 45 & Wharf & 38 \\
\hline 21 & Water transport & 63 & 46 & $\begin{array}{l}\text { Cultural relics } \\
\text { protection }\end{array}$ & 38 \\
\hline 22 & Jianbi Sluice & 62 & 47 & Runzhou & 37 \\
\hline 23 & River outlet & 62 & 48 & Tang dynasty & 37 \\
\hline 24 & Excavate & 61 & 49 & Grain & 36 \\
\hline 25 & Inherit & 60 & 50 & Booming & 36 \\
\hline
\end{tabular}

${ }^{1}$ Danyang is the county-level city in charge of Zhenjiang.

\subsection{Theme Classification of the Projected Image}

To explore the connotation of the projected image, the word was classified and summarized into six themes: shipping traffic, historical figure, natural environment, architectural relic, cultural product, military warfare, literature and art (as shown in Table 3). Among the six themes, the most frequent was shipping traffic, and the least frequent was literature and art.

Historical figures were a category with a high frequency, including characters such as emperors, men of letters, poets, farmers, ministers, generals, etc. The most frequent was the image of the emperor. Successive emperors promoted the development of the ZGC. For example, Sun Quan built the Tieweng City, continued to open the Ganlu Outlet and constructed Po Gangdu; Emperor Yang of Sui excavated the earliest Beijing-Hangzhou Grand Canal. It is the earliest and longest artificial river excavated in the world.

Architectural relic and natural environment were themes that appeared more frequently. The word that appeared the most was "bridge" under the theme of architectural relics, and another is "ecology", which appeared under the theme of natural environment. The bridges are built on the canal and scattered in the corners of the ancient towns, which are rich in history, human value or individual characteristics. Some of the bridges are named after people, some are named after the gates of their proximity to the city gate and some are named after legends. Through appreciating these bridges, tourists can learn the history and culture of the canal. 
Table 3. Topic classification of cognitive image.

\begin{tabular}{|c|c|c|}
\hline Category & High-Frequency Words (Top 20) & Frequency \\
\hline Shipping traffic & $\begin{array}{c}\text { river course/cao yun/river mouth/ship/water conservancy/channel/water } \\
\text { transport/shipping/wharf/grain/ferry/customs/navigation lock/hub/channel } \\
\text { segment/waterway/canal/business/port/estuary }\end{array}$ & 693 \\
\hline Historical figure & $\begin{array}{c}\text { Qin Shihuang/Qianlong/Sun Quan/Sui Yangdi/Pearl Buck/Han Shizhong/King } \\
\text { Wu/Liu Yu/Kangxi/Li Po/Lv Meng/farmer/Guangxu/Emperor } \\
\text { Wen/minister/Daoguang/Fan Zhongyan/Liang Wudi/Liu Bei/Lu You }\end{array}$ & 221 \\
\hline Natural environment & $\begin{array}{l}\text { ecology/scenery/landscape/rivers/environment/river water/lake water/scene/ } \\
\text { surface of a river/landscape belt/beautiful scenery/lake/lake surface/season/ } \\
\text { afforest/bright moon/green brick/spring breeze/grey tile/early morning }\end{array}$ & 211 \\
\hline Architectural relic & $\begin{array}{c}\text { bridge/wall/ancient city/ancient } \\
\text { street/block/stage/pagoda/street/sculpture/ancient bridge/stone } \\
\text { beast/remains/ruins/mausoleum/restaurant/town/former home/ } \\
\text { pavilion/temple/city gate }\end{array}$ & 210 \\
\hline Cultural product & $\begin{array}{c}\text { cultural relic/diet/program/taste/aromatic vinegar/Yao Meat/delicious } \\
\text { food/pot noodles/famous dishes/silk/specialty/dialect/large } \\
\text { meatball/flavor/skill/noodle/ } \\
\text { make wine/polished glutinous rice/exorcise evil spirits/silk weaving }\end{array}$ & 135 \\
\hline $\begin{array}{l}\text { Military } \\
\text { warfare }\end{array}$ & $\begin{array}{c}\text { military/army/war/concession/liberate/station troops/First Opium } \\
\text { War/Zhenjiang Army/Beifu Army/army provisions/anti-gold general/Japanese } \\
\text { troops/officers and men/Taiping Army/treaty/war } \\
\text { disorder/occupy/station/aggressor/headquarters }\end{array}$ & 128 \\
\hline $\begin{array}{l}\text { Literature } \\
\text { and art }\end{array}$ & $\begin{array}{l}\text { poet/Dream Brook Sketchbook/regular script/verse/stone carving/Legend of the } \\
\text { White Snake/horizontal inscribed board/famous phrases/famous } \\
\text { works/poetry/men of letters/couplet/inscription/calligrapher/picture } \\
\text { scroll/mural/Literary giant/litterateur/Song of Inspector Ding/the ancestor of big } \\
\text { characters }\end{array}$ & 110 \\
\hline
\end{tabular}

\subsection{Social Network Analysis of Cognitive-Emotional Image}

The Chinese word segmentation results of network content were divided into cognitive and emotional images through part of speech, and the word frequency was visualized by the word cloud module, as shown in Figure 3. The higher the word frequency, the larger the font size, and vice versa. "River course" and "water transport" were the most common cognitive images, whereas "booming" and "bustling" were the most common emotional images. The results reflected that the cognitive image was mainly the material heritage of the ZGC. The emotional image was positive, mainly describing the prosperity of the Grand Canal in ancient times.

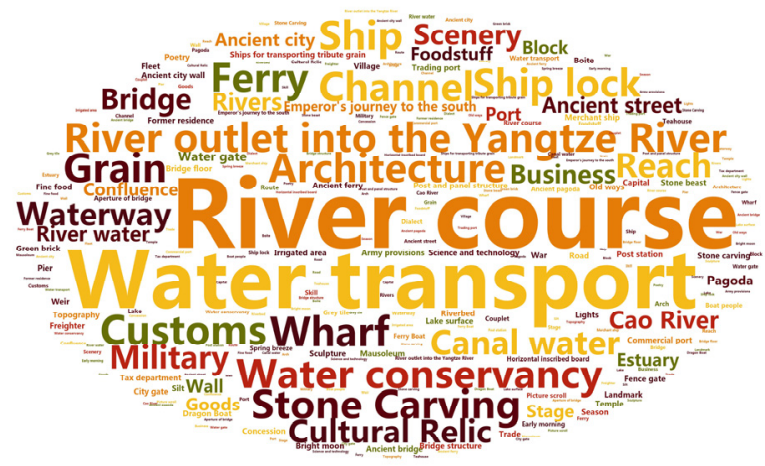

(a)

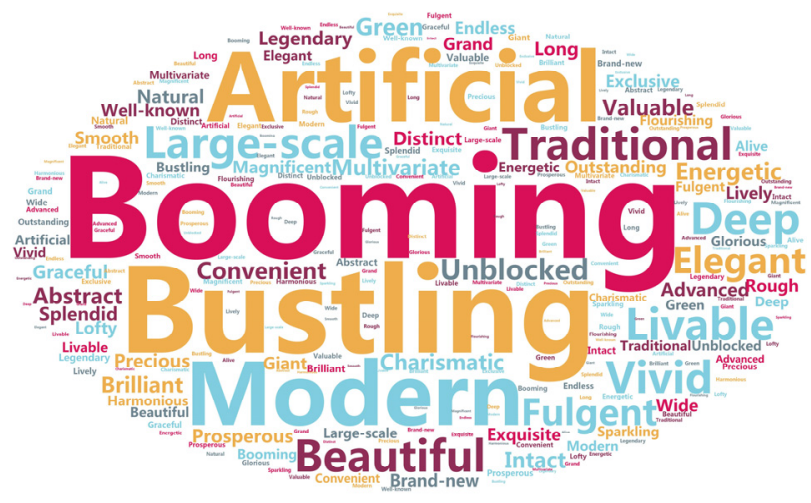

(b)

Figure 3. Cognitive-emotional image word cloud map. (a) Cognitive image; (b) Emotional image. 
As shown in Figure 3a, the cognitive image mainly included three aspects: (1) water conservancy facilities and ecological environment, such as sluice, ferry, river water and riverbed; (2) supporting facilities built around the canal, such as bridges, ancient cities, ancient streets, etc.; (3) derivatives of the canal culture, such as cultural relics, food, poetry, etc. Some freehand and symbolic images appeared in the cognitive images, mainly from classical Chinese poetry, such as light, blue brick, lake surface, bright moon, spring breeze, boatmen, arches, gray tiles, etc. As shown in Figure 3b, most of the emotional images had a positive emotional tendency. The canal and the urban economy were inseparable, and many emotional factors were related to the economy.

The article built a semantic network model, which was used to show the relationship between cognitive-emotional image, as shown in Figure 4. The blue nodes represented cognitive elements, and the red nodes represented emotional elements. The size of the node reflected the centrality of the element in the network. Through centrality analysis, it could be found that the centralities of "architecture" and "ancient city" were the highest among the cognitive elements and the centralities of "booming", "bustling" and "traditional" were the highest among the emotional elements. After reorganizing, the overall image of the ZGC could be summarized as "traditional architecture", "bustling ancient city" and "beautiful ancient bridge".

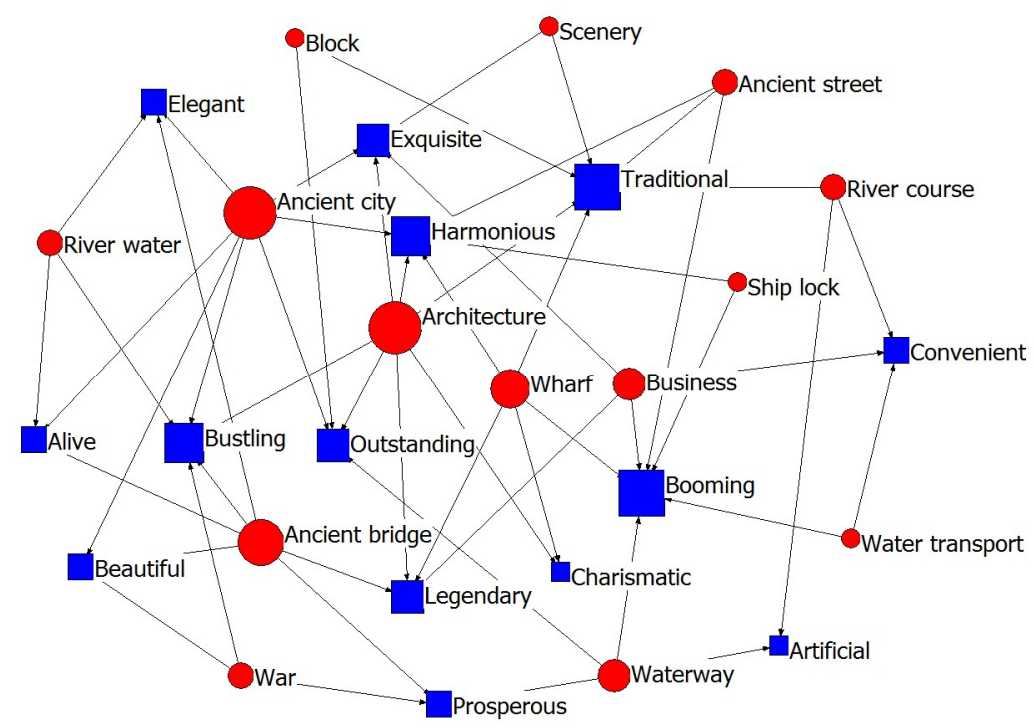

Figure 4. Social network of cognitive-emotional image.

\subsection{Spatio-Temporal Analysis of the Cultural Heritage}

The Grand Canal is not only a world-class cultural heritage but also a linear cultural heritage belt. The distribution and marketing of cultural heritage resources determine whether the ZGC has the potential for tourism development. According to the "Requirements for the Application of World Cultural Heritage Sites and Sections of the Grand Canal", this article divided the canal heritage into three categories: canal hydraulic heritage, canal subsidiary heritage and canal related heritage. Three categories included 14 subcategories, such as river courses, lakes and ship locks. The sunburst map was used to clearly present the composition of cultural heritage (as shown in Figure 5). 


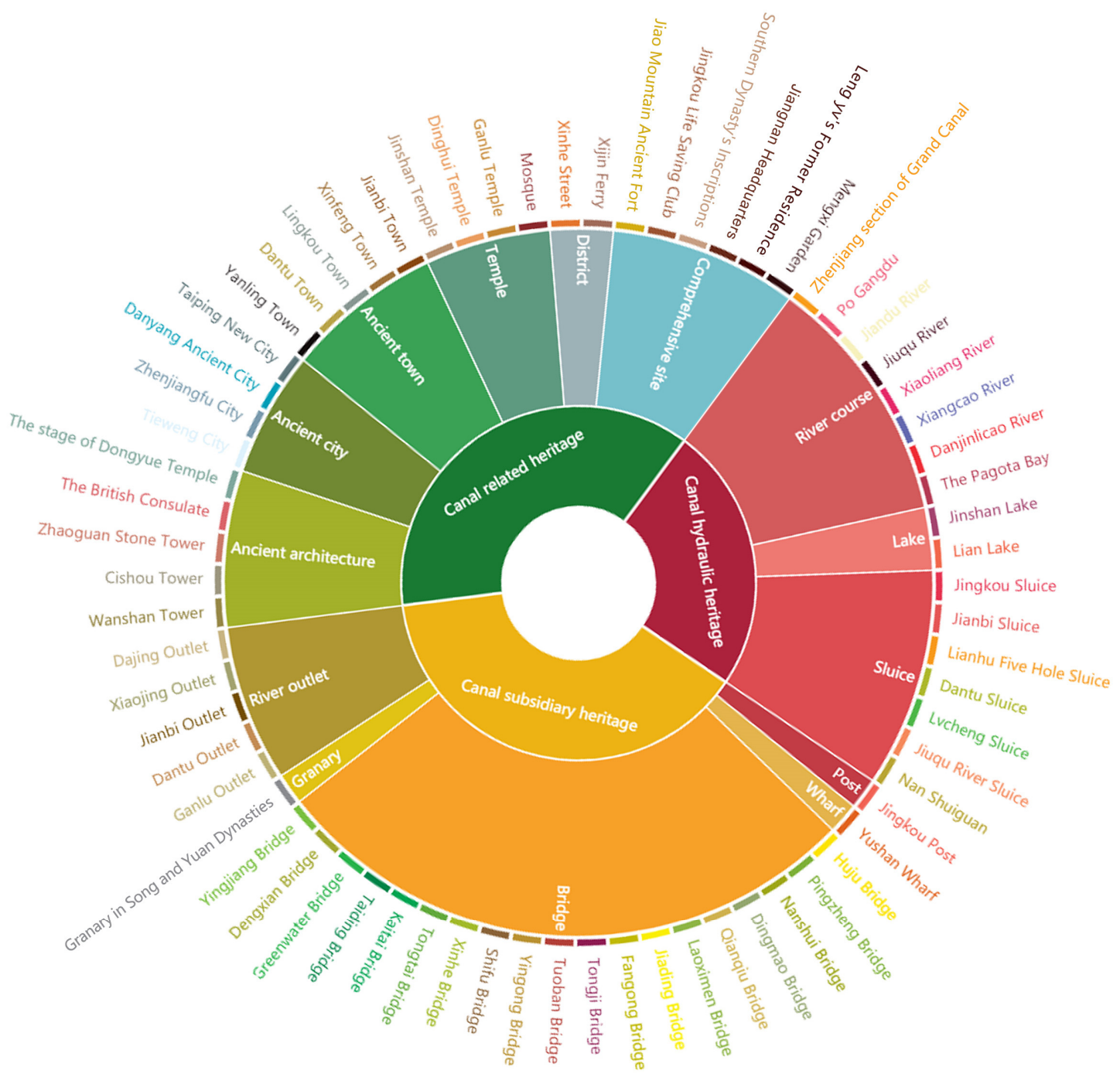

Figure 5. Overview of cultural heritage of ZGC.

It could be seen from Figure 6 that the word frequency of "Xijin Ferry" was the highest. "Jiuqu River Sluice", "Tongji Bridge", "Dengxian Bridge" and "Mosque" had the lowest frequency of words. Except for the heritage sites that were relatively mature and still in use, such as "Xijin Ferry", "Jingkou Sluice" and "Jianbi Sluice", the spread of other cultural heritage was not high. The number was mostly lower than the average word frequency $(A W F=13.9)$. From the category point of view, the average spread of historical and cultural district was the highest, while the post was the lowest (AWF Historical and cultural district $=$ 67.50, AWF Post = 0.01). In each category, "Lian Lake", "Jianbi Sluice", "Yushan Wharf", "Kaitai Bridge", "Granary in Song and Yuan Dynasties", "Xiaojing Outlet", "Wanshan Tower", "Tieweng City", "Jianbi Town", "Jinshan Temple" and "Xijin Ferry" had the highest frequency of words. 

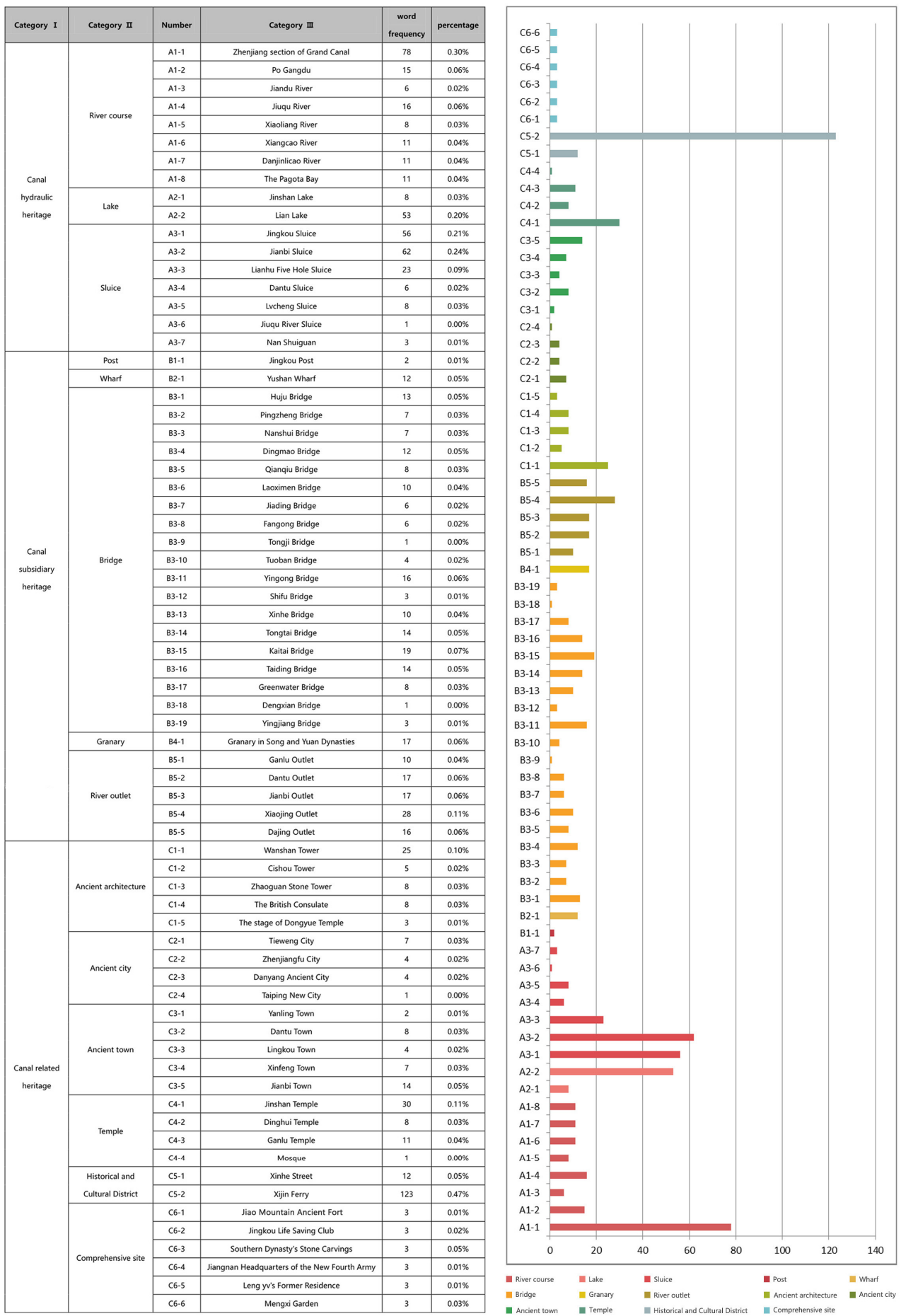

Figure 6. Word frequency analysis of cultural heritage of ZGC.

\subsubsection{Temporal Analysis of Cultural Heritage}

In this paper, an enriched bubble chart was made according to the word frequency and quantity of cultural heritage (as shown in Figure 7). The larger the circle, the more the number of heritage sites. The darker the circle color, the higher the word frequency. The abscissa is the earliest dynasty of cultural heritage with archaeological evidence. From the temporal evolution of 70 cultural heritage sites, Song Dynasty was the heyday of the ZGC, when the categories of cultural heritage were the most comprehensive. There were several burst points in the picture: 
(1) The river course of Qin Dynasty, specifically the Dantu Channel dug by Qin Shi Huang in $210 \mathrm{BC}$, which connected with the canal dug by Fu Chai, the king of Wu, was the embryonic form of Jiangnan Canal.

(2) Lian Lake, which was founded in the Western Jin Dynasty, was the most important economic transportation project of Jiangnan Canal. After more than 1600 years, Lian Lake had played an important role in the regulation, storage and irrigation of the western Tai Lake basin.

(3) The most influential historical and cultural district of the Tang Dynasty was Xijin Ferry. Xijin Ferry, located in the west of Zhenjiang, was formed in the Three Kingdoms period and had a complete ferry function in the Tang Dynasty. There are many historical and cultural relics and groups of traditional residential houses since the Tang Dynasty. It is the oldest, largest and best-preserved old ferry and historical district, and is known as "China Old Ferry Museum".

(4) Various heritage forms closely related to the canal in the Song Dynasty were mature, among which Jingkou Sluice, Granary in the Song and Yuan Dynasties and so on are most prominent.

(5) Kaitai Bridge is the most famous bridge in the Ming Dynasty. It is the largest and most well-preserved ancient stone arch bridge in Danyang.

(6) Jianbi Sluice is the most representative of modern sluice, which was originally a control gate to divert water from the Yangtze River for irrigation in the west of the lake. In the early 1980s, it became the new entrance gate of Jiangnan Canal, from which ships coming up from North Jiangsu Canal and Yangtze River entered Jiangnan Canal.

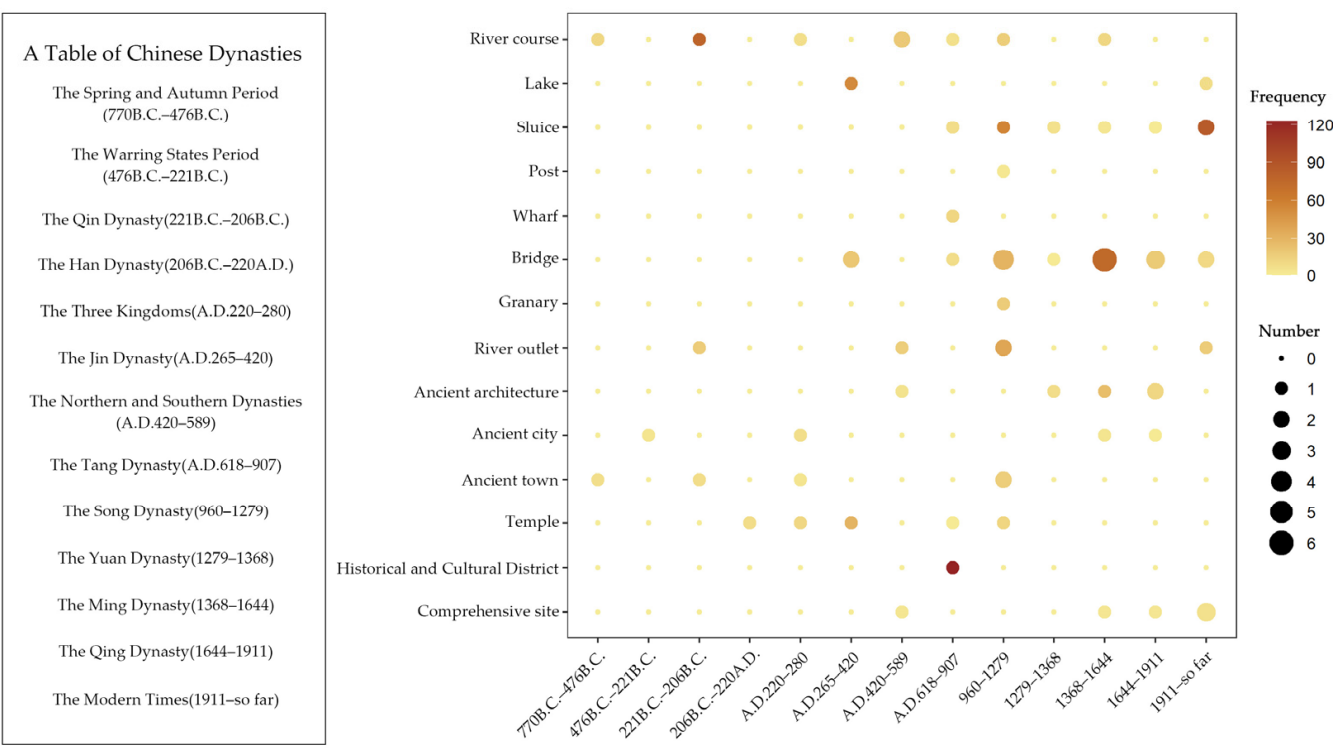

Figure 7. Temporal distribution of cultural heritages of ZGC.

\subsubsection{Spatial Analysis of Cultural Heritage}

According to the geographical location and word frequency of 70 cultural heritages, Figure 8 was made. The position revealed the spatial distribution characteristics of the cultural heritages, and the word frequency showed its activity in network content. The size of the circle in the picture indicated the word frequency, while the color was used to distinguish different types of cultural heritage. 


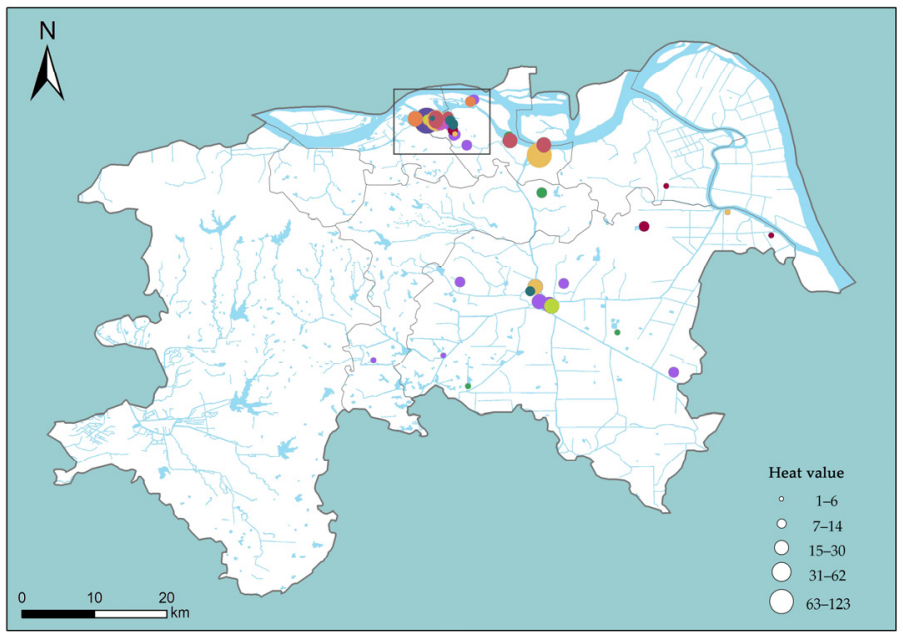

(a) The geographical distribution of cultural heritage

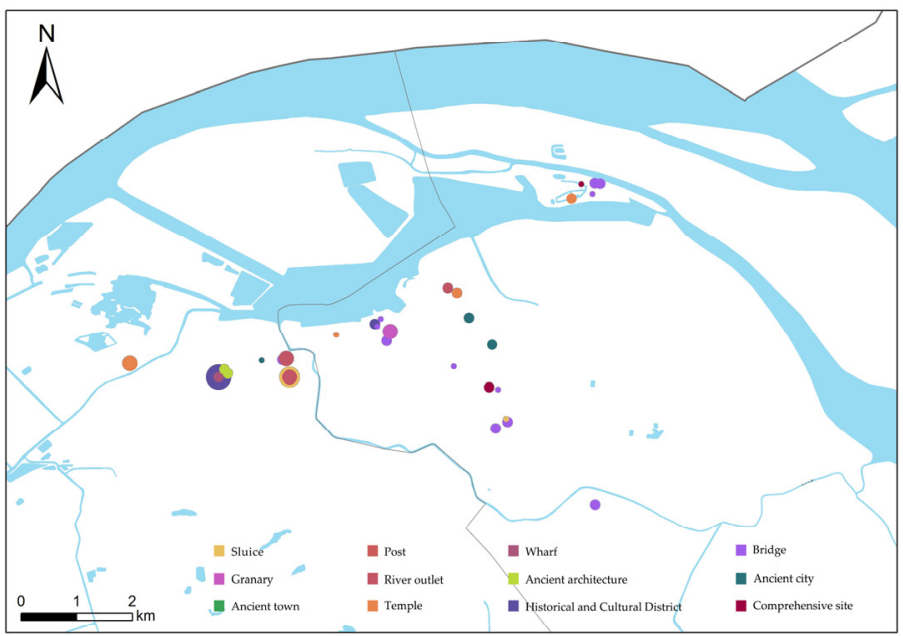

(b) A dense circle of cultural heritage near Jingkou Sluice

Figure 8. Spatial distribution of cultural heritages of ZGC.

As shown in Figure 8a, the characteristic of geographical distribution of cultural heritage was obvious. Most of the cultural heritages were distributed in the river outlet and the intersection of the main canal and tributaries. Among them, the distribution area of bridges is the widest, most of them are built on the river and a few are far away from the river. At the same time, there was a certain rule between word frequency and geographical location. The word frequency of the heritage sites near the Grand Canal was relatively high, while that far away from it was relatively low.

As shown in Figure 8b, the cultural heritage in the Ancient Canal section in Zhenjiang was the densest. A dense circle had been formed at the intersection of the rivers near Jingkou Sluice, where there were nearly 20 heritage sites dotted around. Besides the heritage area of the Ancient Canal in Zhenjiang, Danyang was the main area through which the Grand Canal flowed. Compared with the former, the heritage resources in Danyang were not so rich, and they spread out along the center along the main channel. People generally think that the cultural heritage near the canal is closely related to the canal. Figure 8 shows that some of the cultural heritages were more related to the Yangtze River, such as Qianqiu Bridge, Greenwater Bridge, Shifu Bridge, Jiao Mountain Ancient Fort and Dinghui Temple in the Jiao Mountain scenic spots. 


\section{Discussion and Conclusions}

\subsection{The Theme of the Projected Image}

From the theme of network content, DMO pay more attention to the shipping traffic and exert less publicity on the literature and art of the ZGC. This also reflects from the side that the ZGC is in the comprehensive management stage of ecological restoration and channel expansion at present. It can be seen from Sections 4.1 and 4.2 that there are relatively few vocabularies related to travel in the projected image of $\mathrm{DMO}$, such as transportation, catering and accommodation, which also shows that related tourist attractions of the ZGC are still in the primary tourism development stage, where sightseeing is more than experience.

The psychological distance of tourists to the shipping traffic of the ZGC is relatively large. Studies have shown that the greater the psychological distance, the more common and abstract the internal expression of heritage objects is, and the smaller the psychological distance, the more concrete the background and concept of heritage objects is [45,46]. At present, tourists' awareness of government policies is not high, and the shipping situation is somewhat far from the life of ordinary tourists, which obviously hinders the cultural interest of potential tourists. Tourism managers can consider enhancing tourists' cultural identity by increasing promotion channels and carrying out cultural experience activities.

Literature and art have irreplaceable value in attracting potential tourists, which can even help people understand the culture and status of the Grand Canal. At present, tourists are still trapped in the shallow layer of the heritage tourism experience. Literary and artistic works, such as poems, paintings, movies and television works, can deepen tourists understanding of cultural heritage and make them focus on their inner deep experience. Therefore, to encourage tourists to actively understand the Grand Canal, DMO can start from promoting the content of reading of character stories and appreciating literary and artistic works.

In addition, when tourists' feelings and concerns about a destination are all concentrated on a certain kind of scenery, or when tourists' perception images tend to be similar, the destination image shows the characteristics of solidification. Building a city brand based on local cultural resources is advantageous to shaping a differentiated destination image $[47,48]$. Therefore, DMO can generate more publicity on Zhenjiang's characteristic food culture, celebrities and so on. The industrial chain of the Grand Canal tourism can be extended from the six elements of tourism: eat, live, transportation, travel, purchase and entertainment by building local cultural brands and developing some distinctive guesthouses or restaurants with representative characters' images and stories.

\subsection{Analysis of Cognitive, Emotional and Overall Image of the ZGC}

The cognitive images of the ZGC, which are widely promoted on WOAs, are the river course and water transport. It is the foundation of the formation of the Grand Canal. Around various rivers, water conservancy facilities, such as customs, wharfs and ferries, have been formed. The mutual communication between the rivers has also brought about the prosperity of commercial trade. The river course is closely related to the historical and cultural district; hence, the government can gather more cultural resources into the district to increase the tourism value added to the landscape belt along the river. For example, using water as a medium, a series of water tourism products and night-tour facilities can be developed, such as cruise ships, festival lanterns, etc. Allowing the tourists to experience and participate personally in the cultural exchange of the ZGC can deepen their cultural perception and achieve a better communication effect.

Consistent with the research results of Clemens Költringer [12], the results of this paper once again prove that the sentient value conveyed by DMO is mainly positive, but it seems too idealistic. This goal expression driven by marketing may lead to the loss of its credibility. DMO can increase others' evaluation of the destination to increase credibility. The top 50 high-frequency words hardly involve emotional images. The current canal heritage tourism cannot bring tourists' full emotional experience. However, the 
lack of emotional elements is obviously unfavorable to the tourism development of the ZGC. This kind of superficial tourism mode eventually leads to the aesthetic fatigue of canal heritage tourism. Emotional adjectives strengthen the emotional connection between tourist and place. Research shows that destinations can improve users' response rate on social media and promote a positive destination brand image by using specific emotional brand values $[14,49]$. Throughout the evaluation and description published in WOAs, more keywords are superficial tourism aesthetics, such as "booming" and "traditional", while less deep aesthetic factors are mentioned, which causes the brand image of the canal to remain vague.

DMO project the overall image of the ZGC more than the specific heritage sites. The limitation of offline tourism experience and the deficiency of online marketing jointly lead to this phenomenon. At present, the specific heritage sites of the Grand Canal are not very clear, so the Grand Canal has only a comprehensive impression of the "prosperous ancient canal" in the online text, which is particularly evident in the emotional image, which is mainly caused by the large psychological distance, insufficient publicity of intangible culture and lack of characteristics of the specific heritage sites. In the research of Shi et al. [15], UGC reflects that tourists' cognition stays in the natural landscape and leisure landscape of the Grand Canal, and their understanding of the Grand Canal is also superficial. In fact, the culture of the ZGC is very diverse, and the types of cultural heritage are also very rich. However, the projection image is very single. In the future, DMO need to step up the characteristics of various heritage sites to create a strong overall brand.

\subsection{Nostalgic Characteristics of Brand Image of the ZGC}

Generally, DMO's interpretation of the brand image is that the ZGC is a nostalgic tourist destination full of the color of the times. The cultural belt of the ZGC embodies local customs and practices and scientific and technological wisdom for thousands of years. The quaint architecture focuses on the emotional collision brought by the cultural landscape to tourists; a series of artificial lakes and water conservancy facilities focuses on displaying national wisdom and giving tourists profound educational significance. It is tradition that guarantees the uniqueness of the ZGC and makes it easier to stand out in the global market. Zhenjiang needs to pay attention to the protection and restoration of these ancient buildings and water conservancy facilities and promote residents and foreign tourists to naturally cross between tradition and reality so that the canal culture can really live.

History is the basic element of the formation and development of the Grand Canal, so the projected image of the ZGC has both existing tourist attractions and an image reflecting the scene of the Grand Canal in a specific social background. With the development of the times, some of the heritages are reborn and some disappear, and the role and orientation of the ZGC are changing. "The image of the past" can come from knowledge, such as history and allusions, or from marketing behaviors, such as metaphor [20,50]. Functional, symbolic, experiential association and the attitude to overall brand are identified as the key brand image associations of heritage destinations [51]. For example, images such as "booming water transportation" are descriptions of the ancient Grand Canal. These image associations are processed by literature to describe the picture and set off the atmosphere, which makes the destination image more vivid and artistic and has strong attraction to potential tourists. For today, heritage is the "other" in time. The older the image is, the richer the authentic experience gained in tourism.

Cultural heritage sites have many past characteristics, which can stimulate tourists' nostalgia. Nostalgia is considered as a common emotional expression, which makes people indulge in the surrounding aesthetic and cultural environment symbolizing the past [52]. Lingxu Zhou [20] also mentioned nostalgia in his research, but different from rural tourism, the nostalgic characteristics of the ZGC do not arise from tourists 'memories of childhood but from the awe of history. The popularity of nostalgic culture has opened a new channel for tourism destination marketing. Verma and Rajendran suggested that tourism managers use historical sites and structures to evoke historical nostalgia to attract tourists [53]. To 
develop the tourism of the ZGC, it is important to consider the spiritual expression of image noumenon and reconstruction under imagination and utilization. Therefore, when publicizing the ZGC, marketers restored the prosperity of the Grand Canal in history in the form of the integration of modern technology. This way not only enhances the story and the color of the times but also meets the nostalgic psychology of tourists and helps tourists understand the function of the Grand Canal [54,55].

\subsection{Aanalysis and Protection Strategy of Cultural Heritage}

In terms of time, the cultural heritage of the ZGC originated from the Qin Dynasty and flourished in the Song Dynasty. In terms of space, it is necessary to pay attention to the heritage sites near the river course and river outlet in the development and construction of the Grand Canal. The ZGC in the Song Dynasty, especially in Southern Song Dynasty, is the most important hub section in the canal system and the Yangtze River water transportation system. This study also provides important evidence for this view. At the same time, the construction of heritage sites along the river also supports the necessity of developing water tourism routes in Zhenjiang. As mentioned above, landmarks can help create a more effective online marketing strategy and a stronger competitive image. DMO can take the representative material heritage of each era as the landmark.

Through the analysis of cultural heritage, we can find that material heritage has the greatest influence in the network content of the ZGC. Therefore, the sluice, river course, historical and cultural district have been widely promoted by $\mathrm{DMO}$, and the protection of such heritage is essential for future generations to maintain their lifestyle and the harmony and authenticity of the city. Aside from Xijin Ferry forming a more mature tourism environment, many other cultural heritage scenic spots have not received enough tourists and have a lack of visibility. In order to achieve the sustainable development of the ZGC, DMO need to strengthen publicity efforts in addition to the traditional scenic spots. For sustainable cultural heritage sites, cultural heritage sites need to be reactivated by addressing people's current experiences and interests [56].

\section{Strengths and Limitations}

This study expands the research field and analysis method of the online destination image. First, this study is of great significance to DMO and the projection image. Previous studies mainly focused on the perceptual image instead of the projected image generated by DMO. Investigating the network content generated in WOAs sponsored by DMO can help local governments pay more attention to the operation of social media and the construction of the destination image. Secondly, this study makes a cross analysis of word frequency, time and geographical location, which can generate more comprehensive analysis results. This method is also applicable to the statistical method of big data and can be combined with digital technology, such as digital footprints of tourists $[57,58]$. In addition, the study also enriched the literature of canal tourism. Past research tends to focus on city or place. The method of network content analysis is further extended to heritage sites, which has certain experimental value. Finally, compared with the text mining method used in this study, the sample size of traditional questionnaire analysis is still considered to be small. Larger sample size will enhance the validity and reliability of the result. Natural language processing technology can easily obtain a large amount of unstructured text at a small cost of money and time [59].

However, this study also has some limitations. On the one hand, the source of data is still relatively single and lacks discussion on common and unique dimensions of destination. These refer to the common features shared by destinations and those distinguishing destinations from other choices, which are often the embodiment of destination competitiveness $[60,61]$. In many cases, tourism destinations cannot convey their brand personality, so it is necessary to identify and measure their unique characteristics [32,62]. In the future, we can conduct a comparative study on the destination images of other canal cities. In addition, the perception differences between the same types of cultural heritage can also be 
compared. For example, Xijin Ferry and Xinhe Street are both famous historical and cultural districts of the ZGC. Do they have differences in brand image positioning? This move will help to find the unique image of the ZGC and solve the problem of the homogenization of the destination image. On the other hand, although the analysis of word frequency can show some problems, people still need to combine their semantics to fully understand the text. There are many reasons behind the word frequency. Tourists' attitude towards it may be positive or negative. Therefore, qualitative research or in-depth interviews are needed to provide a more comprehensive explanation of the online destination image.

\section{Future Research Directions}

(1) The effectiveness of destination marketing can be measured by studying the gap or consistency between the projected image and perceived image [14]. Therefore, achieving consistency in destination images is a key goal of destination promoters and marketers, who then intend to assess whether their projected destination images have been conveyed and absorbed by tourists $[63,64]$. Future research can focus on whether there is any deviation between the government's cultural value transmission and the cultural connotation received by tourists before and after travel. The government and urban designers can use these results to reshape or improve the external image of the ZGC according to the deviation of tourists' perceptions.

(2) At present, many emerging media industries have expanded the access to network content. In recent years, many studies have tried to analyze travel photos. Their visual representation of heritage tourism destinations and the analysis of these photos may provide DMO with unique insights $[65,66]$. In China, short videos are very popular, and the emergence of these videos also provides a great deal of text content for the tourism industry, which can basically represent the current situation of cultural heritage communication [67].

(3) The projection image of DMO can be used to refine the theme of the tourism route to meet the personalized needs of tourists. Tourism route planning is carried out under the appropriate heritage interpretation strategy. As a working method, it can promote the understanding and social utilization of heritage sites along the route [68]. Network content can provide valuable insights for potential tourists and help them optimize their destination selection and explore their travel routes or improve their services for tourism practitioners. In the future, different tourism routes can be provided for potential tourists according to the types of cultural heritage and tourists' motivation and preference.

(4) A model using SEM needs to be established to discuss the relationships among the variables. Some previous studies have analyzed the impact of the network content generated by DMO on the destination image $[17,69]$. There is no research to discuss the impact of the marketing communication of DMO on the online destination image, tourists' visit intention and revisit from the perspective of a canal heritage site. Based on this research, we can try to explain the impact of the online platform of DMO on the attraction of cultural heritage from the aspects of nostalgia, psychological distance and emotional image.

Author Contributions: Investigation, Y.Y.; Methodology, W.S.; Resources, C.S.; Supervision, C.S.; Visualization, Y.Y.; Writing-original draft, Y.Y.; Writing—review \& editing, C.S., W.S. and E.K.N.D. All authors have read and agreed to the published version of the manuscript.

Funding: This paper was funded by Postgraduate Research \& Practice Innovation Program of Jiangsu Province (sjcx20-1399) in 2020/ MOE (Ministry of Education in China) Project of Humanities and Social Sciences (20YJC870008) / Key R \& D plan of Zhenjiang City in China (industry prospect and common key technologies) (GY2021014) and general support project of Boutique Engineering Project of Applied Research of Social Sciences in Jiangsu Province in 2021(21SYB-043).

Institutional Review Board Statement: Not applicable. 
Informed Consent Statement: Informed consent was obtained from all subjects involved in the study.

Data Availability Statement: The data is available on https:/ / weixin.sogou.com, accessed on 24 August 2020. The code created in this study is available on https://www.heywhale.com/mw/project/ 621770187c758e0017c4b47b?token=687af8970ca0fc6e\&shareby=5ec1f5d1edcf10002c43c79f, accessed on 24 August 2020.

Acknowledgments: The author would like to thank Yifan Gao, an expert of Zhenjiang Branch of the Grand Canal cultural Belt Construction Research Institute, and Xiaojun Zhang, director of Zhenjiang Municipal Bureau of culture, radio, television and tourism, for their valuable opinions.

Conflicts of Interest: The authors declare that there is no conflict of interest regarding the publication of this article.

\section{References}

1. Ding, F.; Ma, T. Dynamic relationship between tourism and homogeneity of tourist destinations. IEEE Access 2018, 6, 51470-51476. [CrossRef]

2. Vinyals-Mirabent, S. European urban destinations' attractors at the frontier between competitiveness and a unique destination image. A benchmark study of communication practices. J. Destin. Mark. Manag. 2019, 12, 37-45. [CrossRef]

3. Kaplan, A.M.; Haenlein, M. Users of the world, unite! The challenges and opportunities of social media. Bus. Horiz. 2010, 53, 59-68. [CrossRef]

4. Hunter, W.C. The social construction of tourism online destination image: A comparative semiotic analysis of the visual representation of Seoul. Tour. Manag. 2016, 54, 221-229. [CrossRef]

5. Arasli, H.; Abdullahi, M.; Gunay, T. Social Media as a Destination Marketing Tool for a Sustainable Heritage Festival in Nigeria: A Moderated Mediation Study. Sustainability 2021, 13, 6191. [CrossRef]

6. Mak, A.H.N. Online destination image: Comparing national tourism organisation's and tourists' perspectives. Tour. Manag. 2017, 60, 280-297. [CrossRef]

7. Cakmak, E.; Isaac, R.K. What destination marketers can learn from their visitors' blogs: An image analysis of Bethlehem, Palestine. J. Destin. Mark. Manag. 2012, 1, 124-133. [CrossRef]

8. Gabbioneta, C.; De Carlo, M. The role of news articles, prior destination experience, and news involvement in destination image formation. Int. J. Tour. Res. 2019, 21, 291-301. [CrossRef]

9. Nassar, M.A.; Mostafa, M.M.; Reisinger, Y. Factors influencing travel to Islamic destinations: An empirical analysis of Kuwaiti nationals. Int. J. Cult. Tour. Hosp. Res 2015, 9, 36-53. [CrossRef]

10. Jalilvand, M.R.; Samiei, N.; Dini, B.; Manzari, P.Y. Examining the structural relationships of electronic word of mouth, destination image, tourist attitude toward destination and travel intention: An integrated approach. J. Destin. Mark. Manag. 2012, 1, 134-143. [CrossRef]

11. World Tourism Organization. UNWTO Tourism Highlights; UNWTO: Madrid, Spain, 2014.

12. Koeltringer, C.; Dickinger, A. Analyzing destination branding and image from online sources: A web content mining approach. J. Bus. Res. 2015, 68, 1836-1843. [CrossRef]

13. Timur, S.; Getz, D. A network perspective on managing stakeholders for sustainable urban tourism. Int. J. Contemp. Hosp. Manag. 2008, 20, 445-461. [CrossRef]

14. He, Z.; Deng, N.; Li, X.; Gu, H. How to "Read" a Destination from Images? Machine Learning and Network Methods for DMOs' Image Projection and Photo Evaluation. J. Travel Res. 2021, 61, 597-619. [CrossRef]

15. Shi, K.; Zhang, Y.; Liu, Y. Study on Tourists' Perception of the Grand Canal Cultural Heritage Based on Network Travels. In Proceedings of the 2019 IEEE Fifth International Conference on Big Data Computing Service and Applications (BigDataService), San Francisco, CA, USA, 4-9 April 2019; pp. 79-82. [CrossRef]

16. Liang, X.; Xue, J. Online Destination Image Generated by National Tourism Organizations Hosed WeChat Official Accounts. In Proceedings of the 2021 7th International Conference on Information Management (ICIM), Imperial Coll London, S Kensington Campus, London, UK, 27-29 March 2021; pp. 140-143. [CrossRef]

17. Molinillo, S.; Liébana-Cabanillas, F.; Anaya-Sánchez, R.; Buhalis, D. DMO online platforms: Image and intention to visit. Tour. Manag. 2018, 65, 116-130. [CrossRef]

18. Govers, R.; Go, F.M. Projected destination image online: Website content analysis of pictures and text. Inf. Technol. Tour. 2005, 7, 73-89. [CrossRef]

19. Choi, S.; Lehto, X.Y.; Morrison, A.M. Destination image representation on the web: Content analysis of Macau travel related websites. Tour. Manag. 2007, 28, 118-129. [CrossRef]

20. Zhou, L. Online rural destination images: Tourism and rurality. J. Destin. Mark. Manag. 2014, 3, 227-240. [CrossRef]

21. Konwencja UNESCO w Sprawie Ochrony światowego Dziedzictwa Kulturalnego i Naturalnego. 1972. Available online: https://www.unesco.pl/fileadmin/user_upload/pdf/Konwencja_o_ochronie_swiatowego_dziedzictwa.pdf (accessed on 25 August 2021).

22. Henderson, J.C. Conserving colonial heritage: Raffles hotel in Singapore. Int. J. Herit. Stud. 2001, 7, 7-24. [CrossRef] 
23. Tang, L.; Jang, S. The Evolution from Transportation to Tourism: The Case of the New York Canal System. Tour. Geogr. 2010, 12, 435-459. [CrossRef]

24. Guttormsen, T.S.; Fageraas, K. The social production of 'attractive authenticity' at the World Heritage Site of Røros, Norway. Int J. Herit. Stud. 2011, 17, 442-462. [CrossRef]

25. Canale, R.R.; de Simone, E.; di Maio, A.; Parenti, B. UNESCO World Heritage sites and tourism attractiveness: The case of Italian provinces. Land Use Policy 2019, 85, 114-120. [CrossRef]

26. Castillo-Manzano, J.I.; Castro-Nuño, M.; Lopez-Valpuesta, L.; Zarzoso, Á. Assessing the tourism attractiveness of World Heritage Sites: The case of Spain. J. Cult. Herit. 2021, 48, 305-311. [CrossRef]

27. Szubert, M.; Warcholik, W.; Żemła, M. The Influence of Elements of Cultural Heritage on the Image of Destinations, Using Four Polish Cities as an Example. Land 2021, 10, 671. [CrossRef]

28. Beerli, A.; Martín, J.D. Factors influencing destination image. Ann. Tour. Res. 2004, 31, 657-681. [CrossRef]

29. Wang, R.; Hao, J. Gender Difference on Destination Image and Travel Options: An Exploratory Text-Mining Study. In Proceedings of the 2018 15th International Conference on Service Systems and Service Management (ICSSSM), Hangzhou, China, 21-22 July 2018. [CrossRef]

30. Ceylan, D.; Izel, B.; Karaka, H. Destination image perception patterns of tourist typologies. Int. J. Tour. Res. 2020, 23, 401-416. [CrossRef]

31. Ekinci, Y.; Hosany, S. Destination Personality: An Application of Brand Personality to Tourism Destinations. J. Travel Res. 2006, 45, 127-139. [CrossRef]

32. Huete-Alcocer, N.; Martinez-Ruiz, M.P.; López-Ruiz, V.R.; Izquiedo-Yusta, A. Archeological Tourist Destination Image Formation: Influence of Information Sources on the Cognitive, Affective and Unique Image. Front. Psychol. 2019, 10, 2382. [CrossRef] [PubMed]

33. Ginting, N.; Rahman, N.V.; Nasution, A.D. A Comparative Study of Landmark on Heritage Tourism in Sumatra. Environ. Behav. Proc. J. 2020, 5, 221-227. [CrossRef]

34. Prebensen, N.K. Exploring tourists' images of a distant destination. Tour. Manag. 2007, 28, 747-756. [CrossRef]

35. Stylidis, D.; Woosnam, K.M.; Ivkov, M.; Kim, S.S. Destination loyalty explained through place attachment, destination familiarity and destination image. Int. J. Tour. Res. 2020, 22, 604-616. [CrossRef]

36. Kim, S.; Lehto, X.; Kandampully, J. The role of familiarity in consumer destination image formation. Tour. Rev. 2019, 74, 885-901. [CrossRef]

37. Milman, A.; Pizam, A. The role of awareness and familiarity with a destination: The central Florida case. J. Travel Res. 1995, 33, 21-27. [CrossRef]

38. Walmsley, D.J.; Jenkins, J.M. Tourism cognitive mapping of unfamiliar environments. Ann. Tour. Res. 1992, 19, 268-286. [CrossRef]

39. Ryan, C.; Cave, J. Structuring destination image: A qualitative approach. J. Travel Res. 2005, 44, 143-150. [CrossRef]

40. Santos, C.; Neto, M.J.P.; Neves, M. Information Design in Presentation, Interpretation and Dissemination of Natural and Cultural Heritage. In Proceedings of the 2019 10th International Conference on Applied Human Factors and Ergonomics, Washington, DC, USA, 24-28 July 2019; pp. 413-423. [CrossRef]

41. Baloglu, S.; McCleary, K.W. A model of destination image formation. Ann. Tour. Res. 1999, 26, 868-897. [CrossRef]

42. Deng, N.; Li, X.R. Feeling a Destination through the "Right" Photos: A Machine Learning Model for DMOs' Photo Selection. Tour. Manag. 2018, 65, 267-278. [CrossRef]

43. Guimerà, R. "Networks" is Different; Oxford University Press: New York, NY, USA, 2012. [CrossRef]

44. Król, K. Assessment of the Cultural Heritage Potential in Poland. Sustainability 2021, 13, 6637. [CrossRef]

45. Trope, Y.; Liberman, N. Construal-level theory of psychological distance. Psychol. Rev. 2010, 117, 440-463. [CrossRef]

46. Massara, F.; Severino, F. Psychological distance in the heritage experience. Ann. Tour. Res. 2013, 42, 108-129. [CrossRef]

47. Tsai, T.C.; Wang, Y.C. Experiential value in branding food tourism. J. Destin. Mark. Manag. 2016, 6, 56-65. [CrossRef]

48. Lai, M.Y.; Khoo-Lattimore, C.; Wang, Y. A perception gap investigation into food and cuisine image attributes for destination branding from the host perspective: The case of Australia. Tour. Manag. 2018, 69, 579-595. [CrossRef]

49. Lalicic, L.; Huertas, A.; Moreno, A.; Jabreel, M. Which emotional brand values do my followers want to hear about? An investigation of popular European tourist destinations. Inf. Technol. Tour. 2018, 21, 63-81. [CrossRef]

50. Tiago, F.; Correia, P.; Briciu, V.A.; Borges-Tiago, T. Geotourism Destinations Online Branding Co-Creation. Sustainability 2021, 13, 8874. [CrossRef]

51. Goh, E. Understanding the heritage tourist market segment. Int. J. Leis. Tour. Mark. 2010, 1, 257-270. [CrossRef]

52. Nawas, M.P.; Platt, J.J. A future-oriented theory of nostalgia. J. Individ. Psychol. 1965, 21, 51-57.

53. Verma, A.; Rajendran, G. The effect of historical nostalgia on tourists' destination loyalty intention: An empirical study of the world cultural heritage site-Mahabalipuram, India. Asia Pac. J. Tour. Res. 2017, 22, 977-990. [CrossRef]

54. Chen, W.; Zhang, M.; Pan, Z.; Liu, G.; Shen, H.; Chen, S.; Liu, Y. Animations, Games, and Virtual Reality for the Jing-Hang Grand Canal. Comput. Graph. Appl. 2010, 30, 84-88. [CrossRef]

55. Du, X.; Guo, H.; Fan, X.; Tan, J.; Zhu, J. Study on 3D visualization application for the Grand Canal heritage site research. In Proceedings of the 6th International Symposium on Digital Earth: Data Processing and Applications, Beijing, China, 9-12 September 2009; Volume 7841. [CrossRef] 
56. Youn, S.H.; Uzzell, D. The young generations' conceptualisation of cultural tourism: Colonial heritage attractions in South Korea. Asia Pac. J. Tour. Res. 2016, 21, 1324-1342. [CrossRef]

57. Slavec, A.; Sajinčič, N.; Starman, V. Use of Smartphone Cameras and Other Applications While Traveling to Sustain Outdoor Cultural Heritage. Sustainability 2021, 13, 7312. [CrossRef]

58. Wan, C.K.B.; Chow, K.K.N.; Bont, C.J.P.M.; Hekkert, P. Finding synergy between oral and visual narratives on memorable and meaningful tourism experiences. Inf. Technol. Tour. 2020, 22, 107-130. [CrossRef]

59. Liu, B. Web Data Mining; Springer: New York, NY, USA, 2011. [CrossRef]

60. Echtner, C.M.; Ritchie, J.R.B. The measurement of destination image: An empirical assessment. J. Travel Res. 1993, 31, 3-13. [CrossRef]

61. Ritchie, J.B.; Crouch, G.I. The Competitive Destination: A sustainable tourism perspective; CABI: Wallingford, UK, 2003. [CrossRef]

62. Toral, S.L.; Martínez-Torres, M.R.; Gonzalez-Rodriguez, M.R. Identification of the Unique Attributes of Tourist Destinations from Online Reviews. J. Travel Res. 2017, 57, 908-919. [CrossRef]

63. Ji, S.; Wall, G. Understanding supply- and demand-side destination image relationships: The case of Qingdao, China. J. Vacat. Mark. 2015, 21, 205-222. [CrossRef]

64. Marine-Roig, E.; Ferrer-Rosell, B. Measuring the gap between projected and perceived destination images of Catalonia using compositional analysis. Tour. Manag. 2018, 68, 236-249. [CrossRef]

65. McMullen, M. "Pinning" tourist photographs: Analyzing the photographs shared on Pinterest of heritage tourist destinations. Curr. Issues Tour. 2019, 23, 376-387. [CrossRef]

66. López-Chao, V.; Lopez-Pena, V. Aesthetical Appeal and Dissemination of Architectural Heritage Photographs in Instagram. Buildings 2020, 10, 225. [CrossRef]

67. Li, Y.; Xu, X.; Song, B.; He, H. Impact of Short Food Videos on the Tourist Destination Image-Take Chengdu as an Example. Sustainability 2020, 12, 6739. [CrossRef]

68. Leanza, P.M.; Porto, S.M.C.; Sapienza, V.; Cascone, S.M. A heritage interpretation-based itinerary to enhance tourist use of traditional rural buildings. Sustainability 2016, 8, 47. [CrossRef]

69. Sultan, M.T.; Sharmin, F.; Badulescu, A.; Gavrilut, D.; Xue, K. Social Media-Based Content towards Image Formation: A New Approach to the Selection of Sustainable Destinations. Sustainability 2021, 13, 4241. [CrossRef] 